\title{
A imigração haitiana e as mudanças no espaço urbano da cidade de São Paulo
}

Priscilla Pachi ${ }^{1}$

\begin{abstract}
Resumo: Este artigo aborda as mudanças ocorridas no espaço urbano da cidade de São Paulo motivadas pela recente imigração haitiana. De acordo com dados da Polícia Federal, que cobrem o período entre 2010 e 2017, 15.773 haitianos declararam residência na cidade de São Paulo. A partir das formulações teóricas desenvolvidas por Sassen (1993) sobre cidades globais, analisa-se a globalidade da cidade de São Paulo no contexto da realidade brasileira e da periferia do capitalismo onde a inserção desses imigrantes no espaço urbano ocorre, segundo Alain Tarrius (2002), por meio de uma "globalização por baixo" que revela a precariedade da vida que se manifesta como resultado dos baixos salários e da superexploração dessa força de trabalho. Para compor esta análise, foram utilizados registros e dados de pesquisa do OBMigra, da Polícia Federal e do Eixo Trabalho da Missão Paz, em São Paulo. Também foram realizadas pesquisa de campo com base na observação, análise documental e entrevistas com imigrantes haitianos.
\end{abstract}

Palavras-chave: Imigração Haitiana. Espaço Urbano. Trabalho. Moradia. Cidade Global.

\section{Haitian immigration and changes in the urban space of the São Paulo city}

\begin{abstract}
This article addresses the changes that occurred in the urban space of São Paulo's city motivated by the recent Haitian immigration. According to data from the Federal Police, covering the period between 2010 and 2017, 15.773 Haitians declared residence in the city of São Paulo. From the theoretical formulations developed by Sassen (1993) on global cities, the globality of the São Paulo's city is analyzed in the context of the Brazilian reality and the periphery of capitalism where the insertion of these immigrants in the urban space occurs, according Alain Tarrius (2002), through a "globalization from below" that reveals the precariousness of life that manifests itself as a result of the low wages and the overexploitation of this workforce. To compose
\end{abstract}

1 Doutoranda do Programa de Pós-Graduação em Geografia Humana FFLCH- USP, São Paulo - SP, Brasil (priscilla.pachi@usp.br). 
$|2|$

A imigração haitiana e as mudanças...

this analysis, records and research data from OBMigra, the Federal Police and the "Missão Paz" in São Paulo were used. Field research was also carried out based on observation, document analysis and interviews with Haitian immigrants.

Keywords: Haitian Immigration. Urban Space. Job. Home. Global City.

\section{Inmigración haitiana y cambios en el espacio urbano de la ciudad de São Paulo}

Resumen: Este artículo analiza los cambios que ocurrieron en el espacio urbano de la ciudad de São Paulo motivados por la reciente inmigración haitiana. Según datos de la Policía Federal, que abarcan el período comprendido entre 2010 y 2017, 15.773 haitianos declararon su residencia en la ciudad de São Paulo. A partir de las formulaciones teóricas desarrolladas por Sassen (1993) sobre las ciudades, la globalidad de la ciudad de São Paulo se analiza en el contexto de la realidad brasileña y de la periferia del capitalismo donde la inserción de estos inmigrantes en el espacio urbano ocurre, según Alain Tarrius (2002), a través de una "globalización desde abajo" que revela la precariedad de la vida que se manifiesta como resultado de los bajos salarios y la sobreexplotación de esta fuerza laboral. Para componer este análisis, se utilizaron registros y datos de investigación de OBMigra, la Policía Federal y el Eje de Trabajo de la "Missão Paz", en São Paulo. La investigación de campo también se realizó en base a observaciones, análisis de documentos y entrevistas con inmigrantes haitianos.

Palabras clave: Inmigración Haitiana. Espacio Urbano. Trabajo. Morada. Ciudad Global.

\section{Introdução}

A partir de 2010, o Brasil recebeu vários grupos de haitianos motivados por uma série de acontecimentos políticos, sociais e econômicos. Segundo dados do SINCRE, foram registradas aproximadamente $93.000^{2}$ entradas de haitianos, entre 2010 e 2017, pela Polícia Federal em todo o território nacional e, no mesmo período, 15.773 declararam seus domicílios na cidade de São Paulo. Chegam a São Paulo em busca de trabalho para manutenção de suas vidas e para o sustento da família que permaneceu no Haiti por meio do envio de remessas financeiras. A situação vivenciada

${ }^{2}$ Dados do SINCRE. Sistema Nacional de Cadastro e Registro de Estrangeiros. http://obmigra.mte.gov.br/index.php/microdados. Acesso em: 18 fev.2019 
por esses imigrantes na capital paulista requer uma análise das questões relacionadas à habitação e às modificações ocorridas no espaço urbano de São Paulo.

Sassen (2016) considera que o momento atual no mundo é de expulsão social, fatores como pobreza e conflitos políticos são capazes de impulsionar sozinhos as dinâmicas globais de expulsão. Também se intensificam os impactos dos desastres ambientais sobre as populações pobres no mundo. Juntas, essas dinâmicas globais de pobreza extrema, geram grandes deslocamentos onde os desastres ambientais e os conflitos armados criaram níveis de expulsão social.

No que tange ao artigo em questão, foi determinado como objetivo a compreensão de um fenômeno imigratório, cuja amplitude e significação só podem ser captadas pela utilização de métodos condizentes com a complexidade inerente aos fatos, que integram aspectos históricos, sociais e espaciais de sociedades diversas, no caso a haitiana e a brasileira, e sua inserção nos desdobramentos do capitalismo contemporâneo. Como explica Alves-Mazzotti (1998), as pesquisas qualitativas são, em geral, multimetodológicas por incluir grande variedade de procedimentos e instrumentos de coleta de dados. Nesse sentido, procurou-se articular métodos qualitativos - observação, entrevistas e pesquisa bibliográfica e documental - e quantitativos, por meio da aplicação de questionários e análises baseadas na estatística descritiva (LEVIN; FOX; FORDE, 2002). Nessa perspectiva, a combinação de modelos se torna útil para potencializar o conhecimento e dispor de enfoques complementares (SAMPIERI; COLLADO; LUCIO, 2006).

A amostra para a fase quantitativa foi formada a partir dos dados disponíveis do total de imigrantes atendidos pela Missão Paz, mais especificamente pelos atendimentos do chamado "Eixo Trabalho", por dados oficiais obtidos no Ministério do Trabalho, Policia Federal e nos institutos que trabalham e analisam as migrações como o OBMigra (Observatório das Migrações). Os dados do "Eixo Trabalho" até 2018 foram cruzados com os dados obtidos em pesquisa de campo/entrevistas e com a pesquisa do OBMigra de 2016. 
$|4|$

A imigração haitiana e as mudanças...

Na fase qualitativa, foram realizadas 35 entrevistas semiestruturadas com haitianos, em sua maioria na região central da cidade de São Paulo, entre abril de 2017 e junho de 2018. Com base nas respostas obtidas foi possível mapear os locais que esta comunidade habita e frequenta na cidade. Para a realização das entrevistas, foi elaborado um roteiro de perguntas abertas, de modo que fosse criado um espaço de expressão para o entrevistado e que possibilitasse ao entrevistador aprofundar tópicos e descobrir novas formas de abordagem do tema de pesquisa.

A escolha dos entrevistados não seguiu nenhuma seleção pré-estabelecida. Desse modo, prevaleceu a heterogeneidade do grupo entrevistado em termos de gênero, nível de escolaridade, local de origem no território haitiano, as rotas de chegada ao Brasil, a condição social e as diferentes buscas e possíveis atuações no mercado de trabalho.

Além das entrevistas, foram utilizadas outras técnicas de pesquisa como a observação direta, conversas formais e informais que deram subsídios para identificar e analisar as mudanças que ocorreram no espaço da cidade com a presença dos imigrantes haitianos.

Cabe ressaltar que os deslocamentos das pessoas não se limitam somente a uma mudança e a uma ocupação territorial diferente da sua origem, mas eles devem ser analisados mediante as suas características e impactos sociais, econômicos, culturais e políticos tanto no país de origem quanto no país que recebe esses imigrantes. Segundo Sayad (1998) o itinerário epistemológico dos estudos migratórios é também um ponto de encontro de inúmeras disciplinas: história, geografia, demografia, economia, direito, sociologia, psicologia, antropologia, linguística, ciência política, entre outras.

\section{Imigração Haitiana}

Interessa-nos destacar, que "um dos primeiros grandes fluxos de chegada de pessoas de nacionalidade haitiana ao Brasil data de janeiro de 2010. No entanto, segundo os dados do Instituto 
Brasileiro de Geografia e Estatística (IBGE), há registro da presença de haitianos no país, desde a década de 1940". (HANDERSON 2015a, HANDERSON, 2015b apud HANDERSON, 2016, p. 84).

O ineditismo do porte desse aumento do fluxo migratório haitiano e a complexidade que o envolve é um tema que necessita, portanto, de abordagem sistemática nos diversos campos das ciências sociais. De acordo com Germani (1974), é necessário ter como parâmetro para análise dos processos migratórios não somente os fatores de repulsão e de atração que levam contingentes de população a procurarem outros lugares para se fixar. Devese considerar, nesta perspectiva, condições sociais, culturais, econômicas e políticas tanto no país de origem quanto no destino, isto é, no sistema como um todo.

Estudos recentes dedicados à imigração haitiana como os de Cotinguiba (2014) e de Moraes, Andrade e Matos (2013) fazem uma investigação ampla das razões da emigração e dos fatores de atratividade na sociedade brasileira para os haitianos. Nesse sentido, essas pesquisas apontam as dificuldades históricas vividas pelo Haiti desde sua constituição como país independente no século XIX, sua forma de inserção nas relações capitalistas internacionais e as dificuldades geradas internamente pela persistência da desigualdade social e pela instabilidade política, que forçam a população haitiana a buscar alternativas fora de seu país.

Conforme apontam Magalhães e Baeninger (2016) a história do país caribenho é marcada por uma situação política e social críticas desde a sua origem e o país sofreu várias invasões, tentativas de ocupação e bloqueio econômico por parte da França, da Inglaterra, da Espanha e dos Estados Unidos após a conquista da sua independência em 1804.

Em 30 de abril de 2004, o Conselho de Segurança das Nações Unidas cria a Missão das Nações Unidas para a Estabilização do Haiti - MINUSTAH, liderada pelo Brasil. Os principais objetivos da missão eram: estabilizar o país, pacificar e desarmar grupos guerrilheiros e rebeldes, promover eleições livres e formar o desenvolvimento institucional e econômico do Haiti. 
$|6|$

A imigração haitiana e as mudanças...

Como não bastasse, a situação política, civil e econômica críticas do Haiti, em 12 de janeiro de 2010, um forte terremoto atinge o país. Milhares de pessoas ficam desabrigadas e a principal cidade, Porto Príncipe, é completamente destruída. As condições precárias passaram a afetar a vida dos sobreviventes.

Segundo Déus (2017),

\begin{abstract}
Antes do referido terremoto, o país já estava enfrentando problemas de diversas ordens, que podem ser sintetizados na palavra insegurança: pública, política, socioeconômica, alimentícia, educacional, relativa à saúde, ao saneamento básico, entre outros fatores. $\mathrm{O}$ terremoto apenas agravou $\mathrm{o}$ difícil quadro do país, deixando tanto o Estado quanto a população numa situação de perplexidade. Assim, diante dos grandes danos causados pelo terremoto, o Estado se tornou impotente não só para atender às novas demandas da população, mas também para negociar com a comunidade internacional e controlar as ONGs que atuaram no Haiti, principalmente depois da tragédia. Ou seja, o terremoto apenas agravou e dificultou ainda mais a possibilidade de uma atuação política adequada e eficaz por parte do Estado. (DÉUS, 2017, p. 209)
\end{abstract}

Atualmente, o desemprego atinge entre 70 a $80 \%$ da População Economicamente Ativa (PEA) do Haiti. Com uma população de aproximadamente 10 milhões de pessoas, estima-se que apenas 180 mil possuam empregos formais; $80 \%$ da população vive com menos de 2 dólares por dia, ou seja, abaixo da linha da pobreza ${ }^{3}$. "Mesmo nos anos que se seguiram ao terremoto, a promessa de reconstrução do país não aconteceu de forma eficiente, deixando de incluir grande parte da população que permaneceu à margem." (NOGUEIRA, 2017, p. 79)

${ }^{3}$ Disponível em http://www.ihu.unisinos.br/noticias/538630-medo-de-ebolaagrava-preconceito-contra-imigrantes-negros. Acesso em: 20 jan.2016 
Desse modo, com a Região Metropolitana de Porto Príncipe destruída, seus habitantes passaram a migrar para outras regiões do país e para outros países em busca de trabalho, melhores condições de vida e dignidade. Assim, muitos haitianos viram na emigração para o Brasil a possibilidade para darem um novo rumo às suas vidas e migrarem para um destino alternativo e diferente dos que já estavam habituados como a República Dominicana, os Estados Unidos, a França, Bahamas e a Guiana Francesa.

Além do terremoto, é preciso ressaltar que : "Este fluxo é formado a partir de transformações processadas no interior do capitalismo mundial, especialmente relacionados à elevação das seletividades migratórias nos destinos clássicos de migração haitiana como os Estados Unidos e a França." (MAGALHÃES; BAENINGER, 2016, p. 238)

Desse modo, o grande fluxo imigratório de haitianos para o Brasil e seu aumento é comumente associado ao terremoto que destruiu Porto Príncipe, capital do Haiti, em 2010, impondo severas limitações à sobrevivência e subsistência de seus habitantes. De acordo com Cotinguiba (2014), o terremoto tornou-se argumento explicativo do governo brasileiro e foi reforçado pela mídia de modo geral. Fato é que a entrada desses imigrantes no país intensificou-se em 2011 e 2012.

Na perspectiva brasileira, a primeira década do século XXI é marcada por uma ampliação da inserção internacional do país e por um crescimento econômico propiciado pela estabilidade institucional e pela alta do preço das commodities no mercado internacional. Um dos indicadores e passos importantes para a moderna diplomacia brasileira tem como exemplo sua atuação no Haiti.

Além das relações entre os dois países terem se intensificado com a entrada das forças armadas brasileiras liderando e atuando na MINUSTAH e a presença de empresas também brasileiras no Haiti, outros dois fatores que aproximaram os haitianos do Brasil foram o fascínio pelo futebol brasileiro e o mito da nossa "democracia racial". 
$|8|$

A imigração haitiana e as mudanças...

Cabe mencionar que o haitiano chega ao Brasil com a ideia de que o país é uma "democracia racial", democracia esta que é mascarada por um racismo velado na sociedade. Dessa forma, o imigrante se depara com uma realidade oposta da qual imaginava. O fato do Brasil não ter tido um sistema legal de segregação racial como os Estados Unidos que perdurou até a década de 1960 e o Apartheid na África do Sul até a década de 1980, reforça o mito da democracia racial. Em entrevista concedida à Dantas, Ferreira e Veras (2017) o sociólogo Kabengele Munaga relata que, toda a forma de racismo é um crime, mas no Brasil o racismo velado é um crime que mata duplamente.

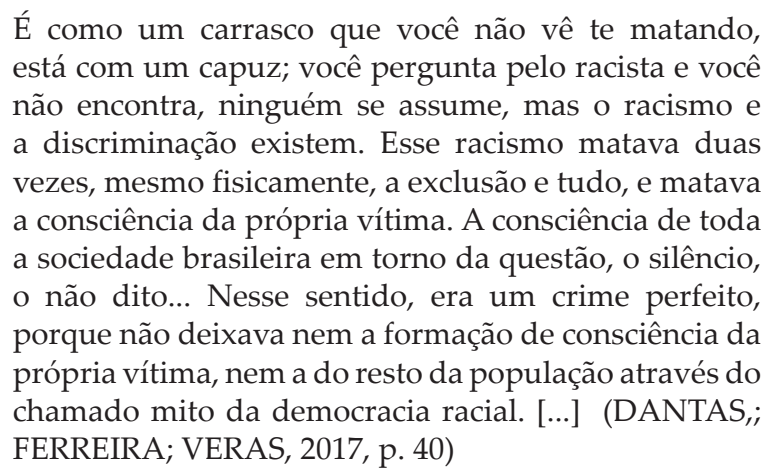

Outros autores brasileiros trabalharam o conceito de democracia racial como é o caso de Gilberto Freyre e Florestan Fernandes. Fernandes (1989) aponta que é um equívoco conceber a sociedade brasileira, com o seu histórico escravocrata, sem preconceito racial e com oportunidades e direitos iguais a todos os seus cidadãos. Os resquícios da escravatura são claros na concepção deste autor que revela a imensa desigualdade no que tange à comparação com relação às posições sociais que ocupam brancos e negros no país. Logo, para Fernandes (1989), enquanto não for concebida a liberdade com a devida igualdade para os negros, o conceito de democracia racial não passará de um mito (FERNANDES, 1989). 
No início dessa imigração, os haitianos chegavam pelo Norte do país e se dirigiam para São Paulo. Neste momento, o Brasil ainda não vivenciava as crises econômica e política e se preparava para os grandes eventos (Copa do Mundo e Jogos Olímpicos) que ocorreriam no país. Encontravam facilmente emprego e havia como absorver essa força de trabalho em alguns setores da economia como a construção civil e serviços. Foi nesse cenário de fartura econômica e de emprego aliado à preparação dos grandes eventos que os primeiros haitianos vitimados pelo terremoto que devastou o Haiti em 2010 começaram a chegar ao Brasil e a se instalarem pelo território nacional.

As medidas adotadas pelo Governo Federal no que diz respeito à regularização dos haitianos no Brasil, seja por visto humanitário ou por residência permanente e pela regularização e ampliação da emissão de vistos a partir de Porto Príncipe, geraram como consequência a diminuição deste fluxo migratório na região Norte e os imigrantes passaram a chegar diretamente por via aérea em São Paulo.

Sem ajuda do governo, chegavam a São Paulo e eram acolhidos pela pastoral na Igreja Nossa Sra. da Paz,no Glicério, região central de São Paulo, e eram atendidos pela Missão Paz ${ }^{4}$.

Já em solo paulistano, recebiam informações da possibilidade de trabalho na capital paulista e em outros estados das regiões Sul e Sudeste. Muitos seguiram para o estado de Santa Catarina para trabalharem na construção civil e nas indústrias de abates de aves e frigoríficos (MAGALHÃES, 2016). Desse modo, cabe salientar que apesar de São Paulo ser um grande polo receptor de imigrantes e com mercado de trabalho mais aquecido, a cidade também é um local de trânsito para as demais cidades e estados do Sul e do Sudeste do Brasil.

Em 2008, uma forte crise econômica se inicia no Hemisfério Norte e se estende para outros países e continentes. Em 2011,

${ }^{4}$ A Missão Paz é uma obra dos Missionários de São Carlos - Scalabrinianos. Com larga vivência junto aos migrantes, imigrantes e refugiados em São Paulo. 
já no governo da presidenta Dilma Rousseff, a crise se instala e as commodities sofrem uma grande desvalorização que afeta a economia brasileira, dependente da exportação de produtos como soja e minério de ferro. Para Antunes e Druck (2014), a crise atual estrutural é simultaneamente uma crise da acumulação do capital até agora nunca vista, manifesta-se pelo seu caráter universal, com alcance global e sendo sua escala temporal extensa, contínua e permanente.

Atualmente, verificamos que, apesar das crises econômica e política vivenciadas pelo Brasil, os haitianos continuam chegando a São Paulo, em número muito reduzido se comparado ao início da década de 2010, mas continuam chegando em busca de trabalho e melhores condições de vida.

Os gráficos abaixo revelam o fluxo de entrada de haitianos no Brasil, no estado de São Paulo e no município de São Paulo respectivamente. É possível verificar que os gráficos comportamse da mesma maneira e que o aumento é gradual em todos eles de 2010 a 2015 atingindo o seu ápice em 2016. A partir de então o fluxo migratório diminui em consequência da crise econômica que atingiu o Brasil e gerou desemprego também entre os haitianos no país.

Gráfico 1: Entrada de haitianos no Brasil

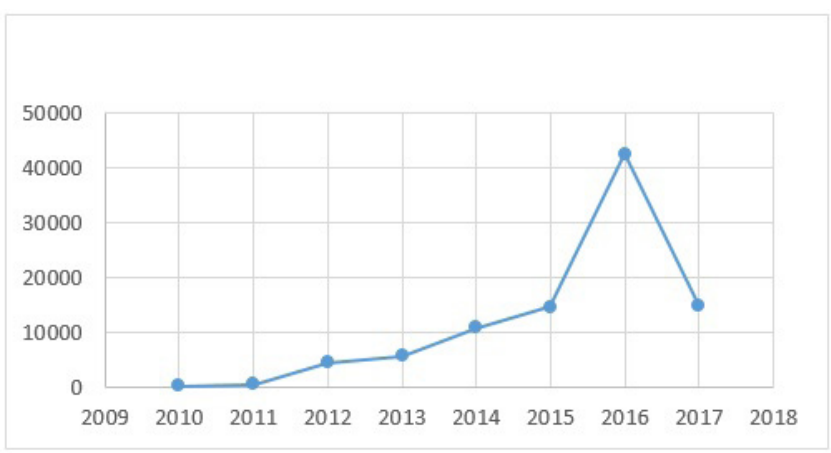

Dados obtidos do Sincre ${ }^{5}$ - elaboração própria

${ }^{5}$ Dados do SINCRE. Sistema Nacional de Cadastro e Registro de Estrangeiros. 
Gráfico 2: Entrada de haitianos no Estado de São Paulo

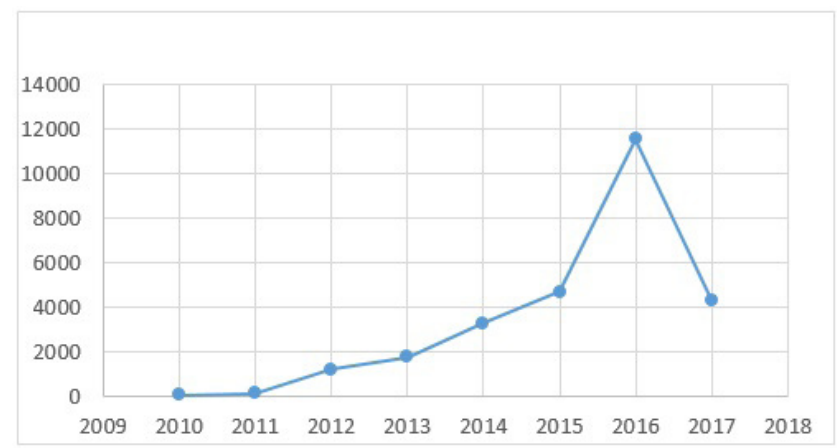

Dados obtidos do Sincre - elaboração própria

Gráfico 3: Entrada de hatianos no município de São Paulo

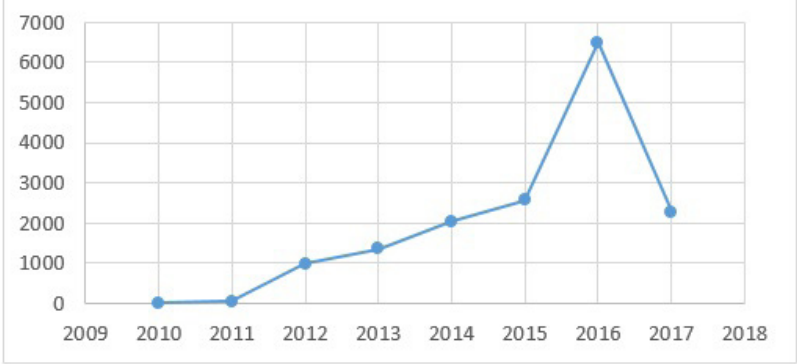

Dados obtidos do Sincre - elaboração própria

Assim sendo, a partir de 2014, o quadro econômico e político do Brasil tornou-se bem diferente daquele encontrado pelos haitianos anos atrás, no início dessa imigração. Em paralelo à crise econômica, instala-se uma grave crise política no governo. Frente ao cenário econômico de crise do emprego, muitos imigrantes

Disponível em: http://obmigra.mte.gov.br/index.php/microdados. Acesso em: 18 fev. 2019 
haitianos foram demitidos e não conseguiram outro trabalho. A opção de uma nova migração surge rumo ao Chile como alternativa na busca por trabalho e alguns se aventuraram rumo aos Estados Unidos, mas uma grande maioria é retida na fronteira com o México. Segundo Jesus (2019), desde 2016 cerca de 4 mil haitianos, sendo a maioria proviniente do Brasil, permanecem nas cidades fronteiriças de Tijuana e Mexicali impedidos de entrarem em solo americano.

Como nos ensina Sayad (1998), a falta de trabalho faz o imigrante também desaparecer. "Foi o trabalho que fez 'nascer' o imigrante, que o fez existir; e ele, quando termina, que faz 'morrer' o imigrante, que decreta a sua negação ou que o empurra para o não - ser" (SAYAD, 1998, p. 55).

\section{Os haitianos e a cidade de São Paulo}

É necessário ressaltar que paralelamente à pesquisa, foi desenvolvido trabalho voluntário, desde 2014, por meio de treinamentos de conteúdo intercultural ministrados para os imigrantes e refugiados de língua francesa na Missão Paz pela ONG Sietar ${ }^{6}$ Brasil, o que permitiu também a coleta de infomações que foram essenciais para o estudo dessa imigração na cidade de São Paulo.

Para Antunes (2009) o trabalho é, em si e por si, uma atividade vital, consequentemente necessário para continuidade da vida e do ser social.

Considerando que o trabalho desempenha um papel fundamental na vida dos imigrantes e que estes fazem parte da divisão internacional do trabalho que atravessa fronteiras e precariza as formas de trabalho, pretende-se analisar mais detidamente as relações entre a imigração haitiana e a sua inserção no mercado de trabalho na cidade de São Paulo que revelam, como

\footnotetext{
${ }^{6}$ A SIETAR Brasil é uma Organização Não-Governamental - ONG - composta de membros filiados que se dedicam à pesquisa, ao treinamento e às atividades educacionais no campo das relações interculturais.
} 
consequência, a precariedade no tocante à habitação e à segregação urbana dessa população.

\section{Os imigrantes haitianos e o trabalho na cidade de São Paulo}

Com basenos dados do "Eixo Trabalho", foi possível verificar que os imigrantes haitianos em sua maioria são contratados para trabalhos que não exigem qualificação e que o salário recebido por eles é, em sua maioria, inferior a R $\$ 2.000,00$.

Gráfico 4: Salário médio dos imigrantes haitianos

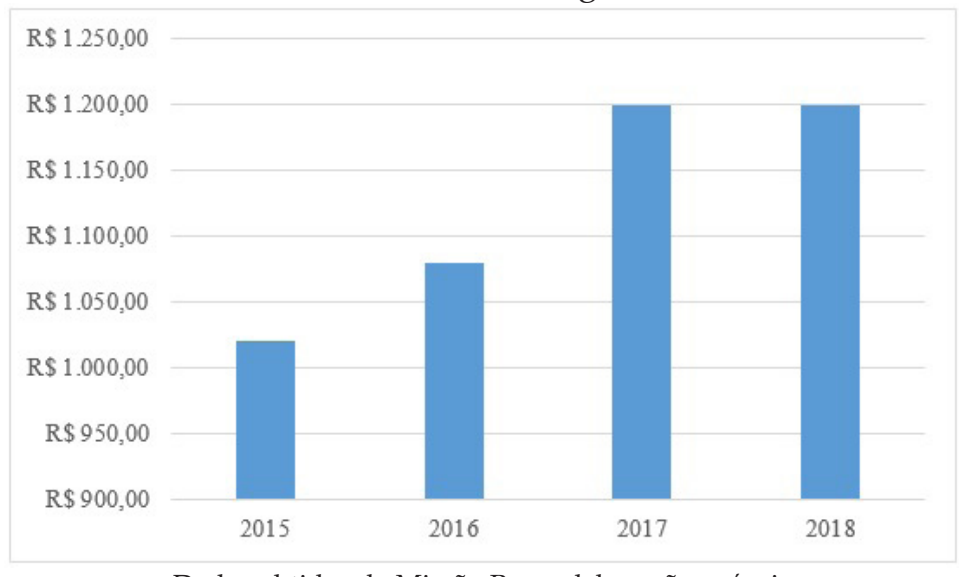

Dados obtidos da Missão Paz - elaboração própria

Desse modo, inserem-se no mercado de trabalho formal em empregos precários e mal remunerados ou destinam-se para a informalidade como forma de garantirem a sobrevivência na cidade. A precariedade do salário se reflete no cotidiano desses imigrantes, pois mal conseguem se manter e utilizam-se de estratégias para economizarem e garantirem o envio de remessas para suas famílias. Essas estratégias incluem o compartilhamento da mesma casa por vários haitianos, a divisão da comida e das despesas mensais. A dificuldade de encontrarem emprego e a precariedade do trabalho que são inseridos revela também, nas diversas esferas da vida, uma imensa precariedade. 
Alguns haitianos expressaram em suas respostas durante a entrevista a precariedade que se manifesta no tocante à moradia e às condições de vida.

“Trabalho num lava-rápido na Mooca e durmo por lá, não tenho dinheiro para morar em outro lugar. O pastor da igreja haitiana da Liberdade também me ajuda com roupa e comida." C.N. 32 anos

"Moro na Armênia com mais três haitianos que conheci aqui no Brasil, dividimos uma casa pequena. Somente uma pessoa trabalha e ajuda com a alimentação." M.V. 40 anos

Abdelmalek Sayad caracteriza e define o imigrante como "força de trabalho provisória, temporária, em trânsito", cuja condição é revogável a qualquer tempo (SAYAD, 1998, p. 54-55). Não se trata, portanto, de qualquer trabalho, mas daquele em que o mercado absorve a mão-de-obra do imigrante. E, ainda, a possibilidade de um estrangeiro se estabelecer em solo alheio só ocorre em sua relação estreita com o mercado de trabalho.

São Paulo, considerada uma cidade global nos termos definidos por Sassen (1993) e que acompanha o fenômeno da globalização, ligado ao desenvolvimento tecnológico, aos serviços de ponta e pela presença de profissionais altamente qualificados, também atrai imigrantes de países da periferia do capitalismo em busca de trabalho e das facilidades que a centralidade da metrópole paulistana proporciona perante o Brasil e o mundo.

Como o conceito de cidade global norteia esta análise, fazse necessário fazer adapatações face à realidade brasileira e da perfiferia do capitalismo, onde se insere São Paulo. Nesse aspecto, a cidade se integra globalmente pela precariedade expressa nas condições e na superexploração do trabalho.

Cabe mencionar que o início da década de 1970 foi marcado pela reestruturação produtiva global que tinha como objetivo a recuperação de seu ciclo reprodutivo por meio da acumulação flexível e teve como características transformações no próprio processo produtivo pautadas pelo avanço tecnológico, pela maior 
participação dos trabalhadores, pela terceirização e pelo trabalho polivalente. Nesse período, as plantas das grandes indústrias se moveram para outras cidades e até mesmo para outros países, porém, uma nova centralidade surge nas antigas metrópoles que passam a sediar empresas de origem quase sempre transnacionais ligadas, em sua maioria, ao setor financeiro e da informação, gerando uma grande transformação na estrutura ocupacional das metrópoles. Essa centralização dos negócios passa a ser exercida pelas cidades globais, ou seja, pelas principais cidades do período fordista que passam a ser identificadas como locais ideais para as funções decisórias e administrativas das corporações.

Desse modo, as últimas duas décadas do século $\mathrm{XX}$ marcaram o surgimento de um tipo específico de cidade que passou a desempenhar, segundo Sassen (1998), as funções de: 1) postos de comando na organização da economia mundial; 2) lugares-chave e mercados para as indústrias financeiras e de serviços especializados; 3) campos de produção e inovação às principais indústrias.

Conforme descreve Carvalho (2000):

“... o conceito de cidade global é a expressão de um processo histórico bastante concreto vivido por determinadas metrópoles do Primeiro Mundo e, como tal, procura refletir a totalidade de seu movimento. Ao mesmo tempo em que designa o processo de transformação na estrutura produtiva das metrópoles, decorrente da globalização da economia, evidencia as contradições a ele inerentes: as alterações promovidas no mercado de trabalho e o aumento consequente da desigualdade social, com rebatimento na apropriação do espaço urbano." (CARVALHO,2000, p. 71)

Ainda segundo Carvalho (2000) ao considerar o conceito de cidade gobal privilegia-se a relação das metrópoles com o processo de globalização em detrimento do conteúdo histórico e das especificidades de cada metrópole o que compromete a análise escamoteando as desigualdades e contradições referentes da apropriação do espaço urbano. 
Tomando como base a condição global da metrópole de São Paulo nos termos propostos por Sassen (1993), é possível dizer que não foi só a globalização do capital e da riqueza que incluíram São Paulo no circuito da globalização, mas também a do trabalho e da pobreza como momento da globalidade da metrópole paulistana. Assim sendo, São Paulo se insere numa trama global no mais amplo universo da acumulação e os imigrantes fazem parte desta engrenagem ocupando trabalhos precários, informais e refletindo a precariedade no cotidiano da metrópole que, conforme Tarrius (2002) descreve, inserem-se na globalização de forma precária por meio de uma mundialização por baixo (mondialisation par le bas).

Tarrius (2002) aponta que o sentido geralmente atribuído à globalização revela as grandes metrópoles como territórios circulatórios usados por milhares de comerciantes informais que transportam e comercializam nas ruas várias mercadorias, em sua maioria contrabandeadas, que preenchem a lacuna da falta de emprego e revelam a precariedade das grandes cidades. $\mathrm{O}$ autor chama de "formigas" os imigrantes que criaram em nivel internacional um mercado onde os contratos e as trocas de mercadorias se organizam segundo suas leis e seus valores. $\mathrm{Na}$ região central da cidade de São Paulo, no entorno da Missão Paz, imigrantes haitianos comercializam produtos de segunda mão, entre eles roupas, sapatos, utensílios de casa, entre outros com preços reduzidos para a população menos favorecida e para os próprios imigrantes.

Para Tarrius (2002), esses imigrantes cuidam de seu destino e ganham muito mais do que os imigrantes trabalhadores formais explorados, precários, superexplorados ou sem documentos. Porém, atuam dessa forma porque não possuem a possibilidade de se inserirem no mercado de trabalho formal.

É válido supor que entre a precariedade citada por Tarrius (2002) e o escamoteamento do conteúdo histórico das metrópoles mencionado por Carvalho (2000) considera-se que o conceito de cidade global defendido por Sassen (1993) não leva em consideração a inclusão precária de trabalhadores, principalmente imigrantes, que reverberam, no caso de uma cidade da periferia do capitalismo como São Paulo, a precariedade de vida como 
resultado dos baixos salários ou da renda recebida pela venda de produtos comercializados na informalidade das ruas da cidade.

Tendo em vista todos os problemas enfrentados pelos imigrantes, desde a dificuldade de reconhecimento do diploma ao elevado desemprego que há no Brasil, é possível dizer que eles estão numa situação de vulnerabilidade que os levam a aceitar qualquer condição de trabalho para sobreviver na capital paulista. Assim sendo, os haitianos estão inseridos em processos de precarização do trabalho onde a economia informal faz parte da economia global e de suas cadeias produtivas. Na impossibilidade de encontrarem emprego formal, os imigrantes se inserem na informalidade e no comercio de rua e articulam redes globais de circulação de mercadorias e de fluxos financeiros contribuindo para a exploração da força de trabalho, também imigrante, de uma cadeia produtiva.

\section{Haitianos e a situação de moradia}

A precariedade proveniente do trabalho e de seus baixíssimos salários também se reflete nas formas pelas quais os haitianos vivem e circulam pela cidade. No que tange à moradia, além da dificuldade para o pagamento do aluguel, há a falta de documentação completa e a impossibilidade de terem um fiador, o que os coloca numa situação complicada, vulnerável e difícil.

Em pesquisa de campo e com base nas entrevistas realizadas, foi possível constatar que a maioria deles mora próximo ao centro da cidade como é o caso da região do Glicério. O fato de a região central da capital ter sofrido uma forte degradação e a região do Glicério apresentar vários imóveis antigos e mal preservados faz com que os cortiços se proliferem e os imigrantes possam alugar e compartilhar um mesmo imóvel para que seja ocupado por várias famílias. $\mathrm{O}$ mesmo processo pode ser observado na região do Cambuci, nas proximidades da Rua do Lavapés. Alugam um quarto e dividem as despesas com outros imigrantes que dormem no mesmo local. Esta forma precária de coabitação permite que "economizem" dinheiro para a garantia do envio de remessas para suas famílias no Haiti. 
Com base nas respostas obtidas nas entrevistas no que tange à moradia, tornou-se possível representar na figura 1 os distritos da cidade de São Paulo que se concentram esses imigrantes. Alguns moram e frequentam regiões mais afastadas do centro da capital e, em outros municípios como é o caso de Santo André, Carapicuíba e Itaquaquecetuba, mas optou-se em representar somente a capital.

Figura 1: Distritos de moradia dos haitianos na cidade de São Paulo, 2019

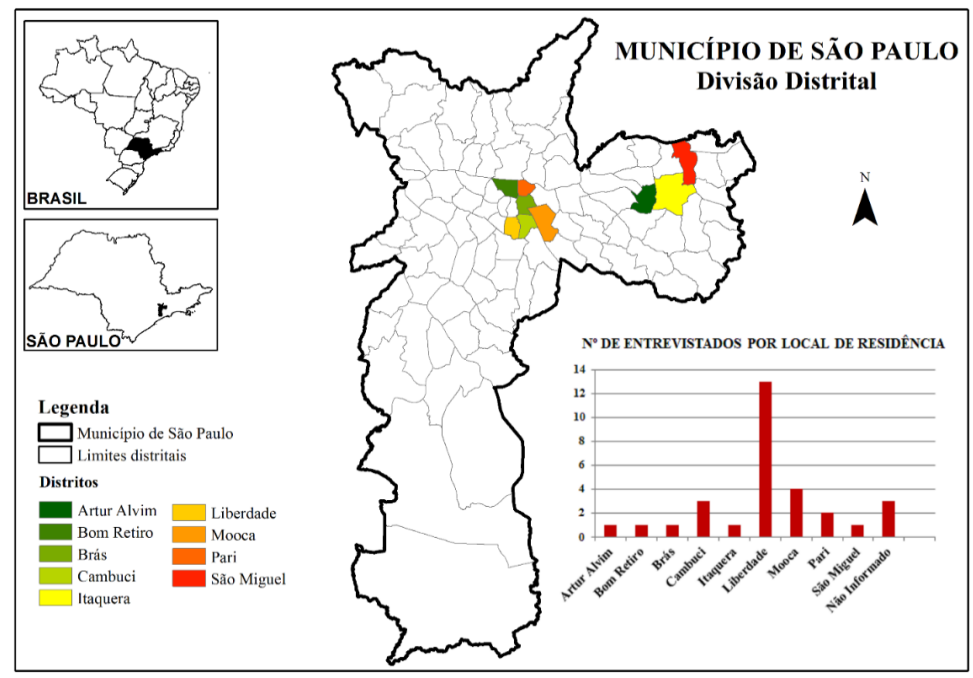

Fonte: elaboração própria

Com base na Figura 1, pode-se afirmar que os sujeitos de pesquisa estão concentrados na região central e na zona Leste da cidade. Eles ocupam o espaço da cidade de várias maneiras e a maior presença deles na região central, como no Glicério, na Liberdade e na Sé, resultou em mudanças significativas nesses locais que tinham, até pouco tempo atrás, a tradição de serem habitados e circularem por eles os orientais, os judeus e representantes de outras nacionalidades.

Com a chegada dos haitianos a partir de 2010 e com a intensificação do fluxo nos anos seguintes, várias mudanças 
ocorreram no espaço urbano e no entorno da Missão Paz, primeiro local de acolhida na cidade.

A rua do Glicério e as ruas próximas que se iniciam nas imediações da estação Liberdade do metrô em direção à baixada do Glicério como a rua dos Estudantes e a rua Conde de Sarzedas apresentam uma série de comércios dirigidos por haitianos e há uma grande circulação deste grupo de imigrantes. É também neste bairro que se encontra a USIH (União Social dos Imigrantes Haitianos) ${ }^{7}$, uma organização criada pelos imigrantes haitianos em São Paulo que tem por objetivo oferecer serviços sociais em âmbito nacional (Brasil) e internacional (Haiti).

É importante ressaltar que, muitos imigrantes, antes de desembolsarem o dinheiro com o pagamento de aluguel, utilizamse dos vários dispositivos gratuitos oferecidos pelas instituições religiosas ou pelo governo. Passam pelo Centro de Referência e Atendimento para Imigrantes (CRAI) da Prefeitura de São Paulo localizado na Rua Major Diogo (Bela Vista) onde podem permanecer por até um ano e na Missão Paz que oferece acolhimento por até três meses aos imigrantes recém-chegados. Há também imigrantes haitianos vivendo em ocupações na cidade, como a Chaparral, na Penha e a do Jardim Piratininga, no Cangaíba, ambas na Zona Leste onde habitam também imigrantes de outras nacionalidades além da haitiana. Participam dos movimentos por moradia como uma forma de "possuírem um teto" que os abrigue, evitando assim a morada nas ruas da cidade.

Após permanecerem na Casa do Migrante da Missão Paz ou passarem pelo abrigo da Prefeitura de São Paulo, os haitianos juntam-se e passam a viver em moradias precárias. Muitos vivem em cortiços na região do Glicério e dividem quartos ou o aluguel de uma casa simples na periferia da cidade de São Paulo.

Os imigrantes haitianos que habitam na periferia da cidade como é o caso do extremo da zona sul e da zona leste da capital assim como, em outros municípios próximos à São Paulo, geralmente possuem um perfil diferente dos que habitam a região central, isto é, em sua maioria conseguiram a reunião familiar e

${ }^{7}$ Disponível em: http://usihaitianos.org/quemsomos/. Acesso em: 17 jan. 2019 
desse modo, o aluguel na periferia se torna mais barato para o pagamento de uma única família.

Desse modo, imigrantes haitianos, devido ao alto custo de vida e do preço abusivo dos aluguéis na cidade, buscam locais mais afastados da região central como é o caso de Guaianases, na zona leste, que oferece facilidade de transporte e preços mais accessíveis com moradia.

Devido à concentração dos haitianos na região central da cidade, pode-se dizer que a modificação do bairro se manifesta de várias maneiras como: pela presença de igrejas com cultos bilíngues; lojas de roupas, acessórios e utilidades domésticas; cabeleireiros, restaurantes e bares de comida típica; oficina de costura; lan house e uma série de outros pontos de comércio cuja propriedade ou o trabalho é realizado por haitianos.

Na Figura 2, destacam-se os locais que os sujeitos de pesquisa frequentam na cidade. É possível verificar que esta circulação se concentra na região central. O mapeamento seguiu a mesma regra da moradia, isto é, foram classificados por distritos.

Figura 2: Distritos frequentados pelos haitianos na cidade de São Paulo

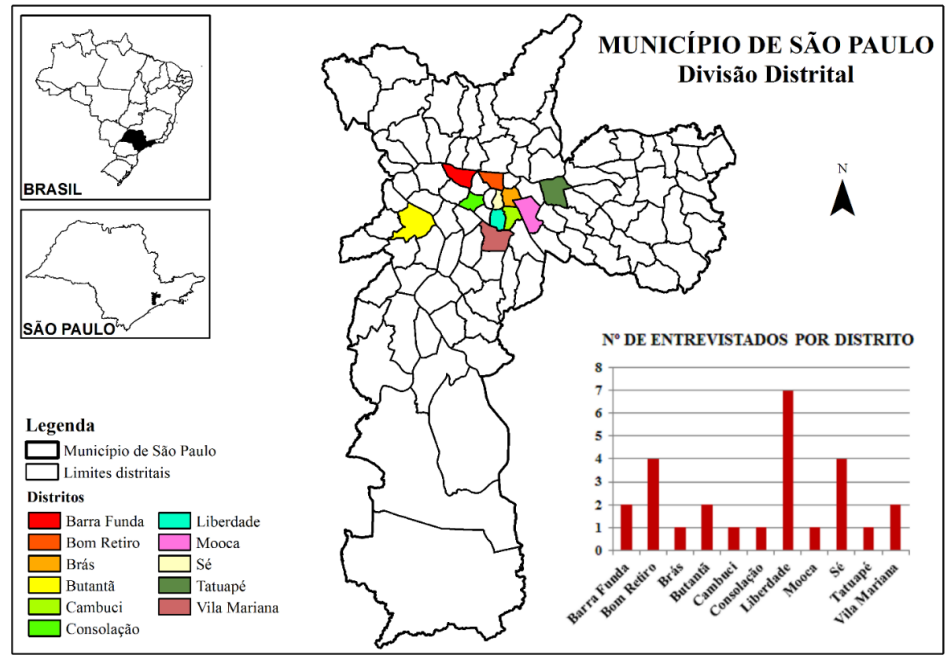

Fonte: elaboração própria 
Como citado anteriormente, o intenso fluxo de haitianos na região central da cidade de São Paulo fez surgir igrejas e novos cultos que modificam o espaço e seu entorno. As igrejas cristãs do bairro do Glicério passaram a oferecer celebrações bilíngues para que os novos fiéis francófonos pudessem participar. Além dos cultos em francês, encontram-se também igrejas que oferecem cultos em créole. Cabe ressaltar que as religiões desempenham um papel fundamental na vida dos imigrantes, pois para além da prática religiosa e da fé, é no espaço da igreja que esses indivíduos se encontram, trocam informações sobre as possibilidades de trabalho e suas experiências de vida e se unem por meio de uma única realidade compartilhada por todos, ou seja, a das dificuldades, da luta coletiva por sobrevivência e pela esperança de dias melhores. As igrejas são extremamente importantes para a integração e socialização da comunidade haitiana que vive em São Paulo.

Assim como no centro da cidade de São Paulo, o bairro da Mooca e Guaianases também apresentam modificações significativas na sua paisagem com a chegada dos imigrantes haitianos. Cultos religiosos também são oferecidos pelas igrejas evangélicas em francês e créole e no comércio local surgiram salões de cabelereiro, restaurantes de comida típica, lan houses e bares comandados ou onde haitianos trabalham.

A informalidade do comércio de rua, principalmente próximo à estação de trem Guainases, é marcada pela presença imigrante. Alguns haitianos que vivem na região central da cidade de São Paulo e que trabalham na informalidade, deslocamse durante o dia para as proximidades da estação de trem para venderem suas mercadorias tendo como premissa a menor fiscalização da Prefeitura na periferia da cidade. Nas entrevistas, no que tange aos locais que frequentam na cidade, deram ênfase aos locais públicos como: praças, parques, cinema, shoppings centers, biblioteca e lugares com wifi onde podem gratuitamente usar o celular e o whatsapp. 
Moro na Rua Lavapés, no Cambuci e estou sempre na Igreja do Glicério para encontrar os outros haitianos. Vou na Praça da Sé e passeio por lá. (V.V. 30 anos)

Frequento a Igreja Deus é Amor, perto do Glicério. Costumo ir à Av. Paulista e no final de semana visito meus amigos que moram em Utinga. (M.C.C. 24 anos)

Moro na Mooca, mas encontro meus amigos também haitianos num bar na rua do Glicério. Frequento a Igreja Deus é Amor e vou ao Parque da Luz. Busco também praças perto do centro da cidade que tem wifi._ (D.F. 31 anos)

Pelo fato de a periferia muitas vezes ser desprovida de equipamentos públicos como praças e museus, muitos imigrantes deslocam-se pela cidade por meio do transporte público em busca de opções de lazer que a região central da cidade oferece. Revelam a importância dada às praças e parques que são citados como locais de lazer e encontro. A praça pública mais citada foi a Sé que retoma aqui o seu significado histórico da palavra "praça" como espaço privilegiado para as discussões políticas e para vida social, considerada como o local do encontro, do lazer e das práticas de socialização. Os haitianos encontram nas praças a possibilidade de contato com seus conterrâneos e um meio gratuito de estreitar laços e fazerem novos conhecidos na cidade. As mulheres disseram que frequentam e gostam de ir aos shoppings centers da cidade. Os mais escolarizados citaram que frequentam bibliotecas, o campus da USP, o SESC, cinema e o museu da Imigração.

Para além da moradia e da circulação pela cidade, eventos organizados pela USIH como foi o caso do "Festival da Cultura do Haiti" realizado em agosto de 2016 no galpão da Vila Itororó, no Bixiga, teve como finalidade divulgar aos paulistanos a cultura haitiana por meio da gastronomia e da música. A música haitiana se destaca nos eventos da comunidade e em festivais pela cidade. Bandas como a Satélite Music, formada em 2014 e a Surprise 69 
da Zona Leste já fizeram apresentações em festivais de música e eventos do Sesc São Paulo e do Museu da Imagem e do Som (MIS). Anualmente, é promovida com o auxílio da Missão Paz e da USIH no dia 18 de maio a festa da bandeira haitiana, que comemora a independência do Haiti e a criação da primeira república negra do mundo (1804). A festa é aberta ao público e realizada no páteo da Igreja Nossa Senhora da Paz do Glicério com comida típica, música e folclore haitiano.

Além dos eventos da comunidade, o protagonismo dos haitianos é marcante na "Marcha dos Imigrantes" realizada anualmente na cidade. Eles participam ostentando a sua bandeira e reinvidicam, junto a outros imigrantes de outras nacionalidades, por políticas públicas voltadas à população imigrante assim como, chamam a atenção da sociedade pelas dificuldades enfrentadas por eles no cotidiano da metrópole.

Outra característica importante a ser considerada na mudança do espaço na região central da cidade, mais precisamente em frente e no entorno da Missão Paz, com a chegada dos haitianos é a presença permanente das "Madames Saras", conforme mostra a figura 3, que são mulheres haitianas que informalmente preparam, comercializam e oferecem produtos alimentícios (frutas e legumes - in natura ou assados) nas ruas. As "Madames Saras" são personagens conhecidas e atuantes nas ruas de Porto Príncipe e, em São Paulo, atuam da mesma maneira, ou seja, reproduzem seu modo de vida haitiano na capital paulista dando um novo significado à paisagem urbana da cidade por meio da atividade informal exercida por elas e que garante, para muitas famílias, a única renda para o seu sustento. Revelam por meio de suas práticas a importância do protagonismo feminino na economia familiar num momento de crise e falta de trabalho generalizada. 
Figura 3: Madames Saras em frente à Missão Paz

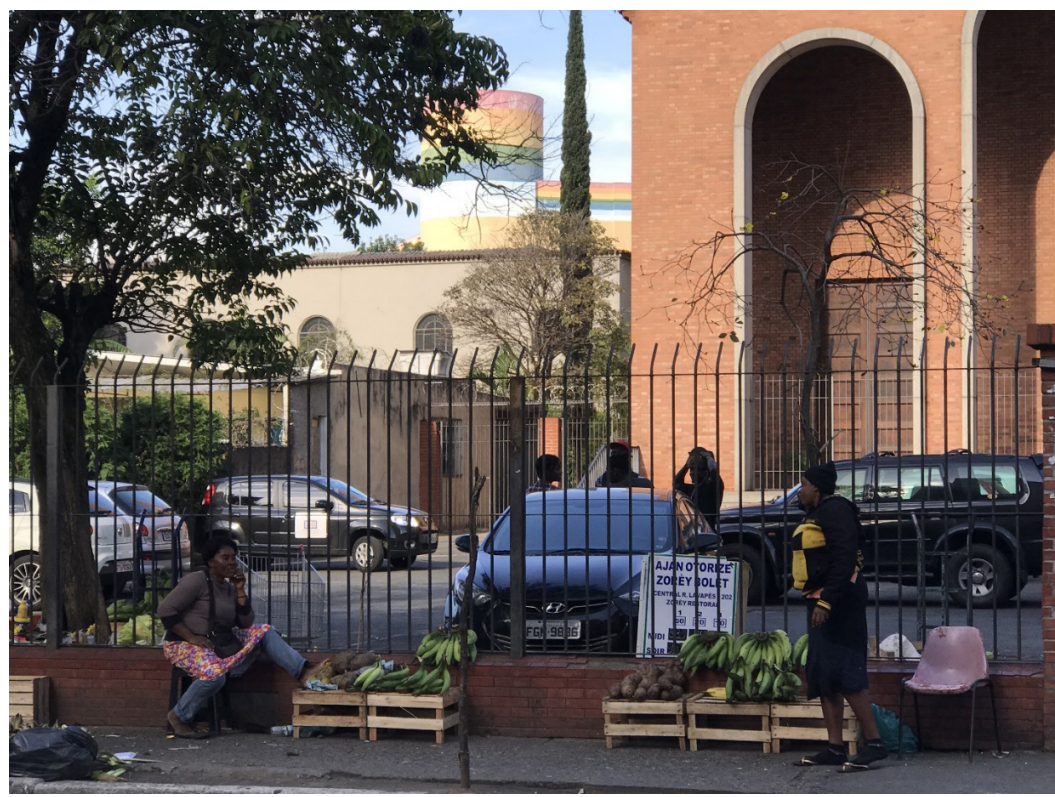

Foto: acervo da pesquisa (2018)

Partindo do pressuposto que o fenômeno migratório é espacial, considera-se que o deslocamento das pessoas se dá de determinados lugares para outros. Quando esses imigrantes ocupam outros lugares, há uma busca pela continuidade e afirmação de sua existência que se dá por meio de sua cultura, seus hábitos, na prática religiosa e na prática do idioma e aprendizado deste para as próximas gerações.

Desse modo, o imigrante mantém a sua identidade e a expressa no âmbito dos lugares que elege para a sua continuidade existencial. A propriam-se dos lugares como forma de estabelecerem com ele sua permanência e o pertencimento na sociedade de acolhida. Nesse sentido, "o lugar é onde o ser pode se realizar. A relação ser-lugar permite ao migrante continuar a ser ele mesmo o mesmo, na medida em que permite o ser manter-se em movimento conjunto às coisas." (GALLO, 2011, p. 52) 
Desse modo, as atividades desenvolvidas pelos imigrantes possibilita a criação na cidade de São Paulo, mais precisamente nas proximidades da Missão Paz, de um espaço com identidade haitiana resultado da forte presença da comunidade, seja pela moradia ou pelas atividades econômicas que desenvolvem no local.

\section{Considerações finais}

Presenciamos, no sistema capitalista neoliberal em que vivemos, um aumento da migração em escala global. As restrições de entrada nos países do Hemisfério Norte se intensificaram após os atentados terroristas de 11/09/2001, limitando ainda mais a livre circulação de pessoas tão defendida no início da globalização. Fato é que as fronteiras se fecham nos países desenvolvidos e a alternativa para muitos migrantes é o Sul global onde o Brasil está inserido.

Desde 2010, o Brasil e a cidade de São Paulo recebem imigrantes haitianos que chegam em busca de emprego e de uma vida melhor. Circulam pela a cidade, locomovem-se utilizando o transporte público, frequentam parques, praças e eventos; falam créole, francês e português com sotoque, dão às ruas uma nova roupagem e à cidade de São Paulo uma nova paisagem marcada pela sua presença.

Sayad (1998) nos ensina que, a migração é um "fato social total" e a chegada do recente fluxo migratório haitiano não modifica somente a paisagem da cidade, mas ele traz consigo um impacto em diversas áreas como na economia, no acolhimento das escolas públicas, nos abrigos e alojamentos públicos e nas entidades que trabalham com migrantes, nos atendimentos do SUS, na percepção da sociedade e na necessidade de se criar políticas públicas para o atendimento das necessidades dessa população e de todos os diversos imigrantes que vivem em São Paulo.

A territorialização dos imigrantes, conforme nos mostra os estudos de Hasbaert (2006) se dá no sentido do engajamento com o mundo do trabalho. A falta de trabalho ou o recebimento de 
salários baixos permite uma territorialização precária na cidade, seja na habitação, na informalidade dos trabalhos temporários ou nos "bicos" exercidos por eles, na alimentação e consequentemente na diminuição ou escassez de envio de remessas para os familiares no Haiti.

Com a presença haitiana, é possível identificar várias mudanças no espaço urbano de São Paulo, mas é necessário destacar a região central e o entorno da Missão Paz, na baixada do Glicério, primeiro local de acolhida na cidade e referência para esses imigrantes que possuem a sua associação no mesmo bairro o que viabiliza a permanência dessa comunidade nesse lugar. Além disso, a região central oferece equipamentos urbanos que, em sua maioria, não são encontrados na periferia da cidade, o que atrai, mesmo os que moram distantes, a procurarem a região central pelas opções de lazer, de serviços e pela facilidade de encontro com outros haitianos.

Após passarem por abrigos gratuitos da cidade, optam por morar em cortiços na região do Glicério, Cambuci e Ipiranga que, antigamente foram habitados por imigrantes de outras nacionalidades ou na periferia e também em outros municípios da grande São Paulo em busca de opções de aluguéis mais acessíveis como é o caso de Guaianases, Itaquera e Mooca, na zona leste e, em bairros do extremo da zona sul. Conforme nos aponta Dal Gallo (2011) "A ontologia do migrante vem à luz, em causa da compreensão da necessidade intrínseca da busca da existência do lugar: o desejo de manter a continuidade da sua narrativa existencial. (GALLO, 2011, p. 56,)

É em busca de manter a continuidade de sua existência que os haitianos se apropriam dos espaços da cidade e manifestam sua cultura e seus costumes por meio de suas atividades laborais, pela música e gastronomia e contribuem para enriquecer a multiculturalidade da metrópole paulistana que outrora recebeu e ainda recebe vários outros fluxos de imigrantes. 


\section{Referências}

ALVES-MAZZOTTI, Alda Judith; GEWANDSZNAJDER, Fernando. $\mathbf{O}$ método nas ciências naturais e sociais: pesquisa quantitativa e qualitativa. 2.ed. São Paulo: Pioneira, 1998.

ANTUNES, Ricardo; DRUCK, Graça. A epidemia da terceirização. In: Ricardo Antunes (org). Riqueza e Miséria do Trabalho no Brasil III. São Paulo: Boitempo, 2014.

CARVALHO, Monica de. Cidade Global. Anotações críticas sobre um conceito in São Paulo. In: Revista Perspectiva 14 (4) 2000 p. 70-82.

COTINGUIBA, Geraldo Castro. Imigração haitiana para o Brasil: a relação entre trabalho e processos migratórios, 2014, 154 p. Dissertação (Mestrado em História e Estudos Culturais) Universidade Federal de Rondônia, Porto Velho, 2014.

DANTAS, Sylvia.; FERREIRA, Ligia, VÉRAS, Maura Pardini Bicudo - Um intérprete africano do Brasil: Kabengele Munanga. Dossiê interculturalidades. In: Rev. USP, São Paulo, n. 114, p. 3144, julho/agosto/setembro 2017.

DEUS, Frantz Rousseau. Migração Haitiana em São Paulo pósterremoto de 2010: A religião como suporte. In: Temáticas, Campinas, 25, (49/50): 203-232, fev/dez. 2017.

FERNANDES, Florestan. Significado do protesto negro. São Paulo: Cortez, 1989.

FREYRE, Gilberto. Casa-grande e senzala. Rio de Janeiro: Record, 2000.

GALLO, Priscila Marchiori Dal. Lugar e identidade na experiência migrante: entre eventualidade e transitoriedade. In: Geograficidade, v.01, n.01, p. 44-58, Inverno 2011.

GERMANI, Gino. Sociologia da modernização: estudos teóricos, metodológicos e aplicados a América Latina. São Paulo: Mestre Jou, 1974. 
HAESBERT, Rogério. O mito da desterritorialização: do 'fim dos territórios' à multiterritorialidade. ${ }^{2}$ a . ed. Rio de Janeiro: Bertrand Russel, 2006.

HANDERSON Joseph. A Historicidade da (E)migração Internacional Haitiana. O Brasil como novo espaço migratório. In. Cavalcante et al (org). A imigração haitiana no Brasil: características sociodemográficas e laborais na região Sul e no Distrito Federal. OBMIGRA, Brasília, 2016.

JESUS, Alex Dias de. Fronteiras e atravessamentos: experiências migratórias de haitianos em Tijuana, México. Formação (Online), v.26, n.49, p. 85-105, 2019.

LEVIN, Jack; FOX, James Alan; FORDE, David R. Estatística para as ciências humanas. 11 $1^{\text {a }}$. ed. São Paulo: Pearson Education Brasil, 2012.

MAGALHÃES, Luís Felipe Aires; BAENINGER, Rosana. Imigração haitiana no Brasil e remessas para o Haiti. In. BAENINGER, R. (org et al). Imigração haitiana no Brasil. Jundiaí: Paco Editorial, 2016.

MAGALHÃES, Luís Felipe Aires. Imigração haitiana no estado de Santa Catarina: contradições da inserção laboral. In. BAENINGER, R. (org et al). Imigração haitiana no Brasil. Jundiaí: Paco Editorial, 2016.

MINISTÉRIO DA JUSTIÇA. Governo brasileiro garante direitos para imigrantes haitianos. Disponível em: http://www.justica.gov. br/noticias/governo-brasileiro-garante-direitos-para-imigranteshaitianos. Acesso em 6 mar. 2016.

MORAES, Isaías Albertin de; ANDRADE, Carlos Alberto Alencar de; MATTOS, Beatriz Rodrigues Bessa. A imigração haitiana para o Brasil: causas e desafios. In: Conjuntura austral, Porto Alegre, v. 4, n. 20, out. nov. 2013, p. 95-114.

NOGUEIRA, Fabiana. Dèyè mòn, gen mòn: Imigração Haitiana no Brasil - Relatos do Vivido, 2017. Tese: (dissertação de mestrado) FFLCH-Programa de Pós- Graduação em Humanidades, Direito e outras legitimidades-USP. 
PACHI, Priscilla. A precarização na base da mundialização contemporânea: a imigração haitiana na metrópole de São Paulo, 2019. Tese: (dissertação de mestrado) FFLCH - Programa de PósGraduação em Geografia Humana - USP.

PACHI, Priscilla. Migração e interculturalidade, um binômio capaz de construir pontes de convivência. In: Rev. UFMG, Belo Horizonte, v. 25, n. 1 e 2, p. 124-143, jan./dez. 2018.

SAMPIERI, Roberto Hernández; COLLADO, Carlos Fernández. LUCIO, Pilar Baptista. Metodologia de pesquisa: São Paulo: McGraw Hill, 2006.

SASSEN, Saskia. Expulsões, brutalidade e complexidade na economia global. São Paulo: Paz e Terra, 2016.

SASSEN, Saskia. As cidades na economia mundial. São Paulo: Studio Nobel, 1998.

SASSEN, Saskia. A Cidade Global. In: LAVINAS, Lena; CARLEIAL, Liana Maria da Frota; NABUCO, Maria Regina. Reestruturação do espaço urbano e regional no Brasil. São Paulo: ANPUR/Hucitec, 1993.

SAYAD, Abdelmalek. A imigração ou os paradoxos da alteridade. São Paulo: Editora da Universidade de São Paulo, 1998.

SINCRE. Sistema Nacional de Cadastro e Registro de Estrangeiros. Disponível em: http://obmigra.mte.gov.br/index.php/microdados. Acesso em: 18 fev. 2019.

TARRIUS, Alain. La mondialisation par le bas: Les nouveaux nômades de l'économie souterraine. Paris : Éditions Balland, 2002.

UNISINOS. Medo de ebola agrava preconceito contra imigrantes negros. Revista Instituto Humanitas. 18 de dezembro de 2014. Disponível em: http://www.ihu.unisinos.br/noticias/538630-medo-de-ebola-agrava-preconceito-contra-imigrantes-negros. Acesso em: 20 jan. 2016.

USIH - União Social dos Imigrantes Haitianos. Disponível em: http://usihaitianos.org/quemsomos/. Acesso em: 17 jan. 2019. 